\title{
Emerging Technologies and Corporate Culture at Microsoft: A Methodological Note
}

\author{
David Klein $^{\dagger}$, James Schmeling ${ }^{\ddagger}$ and \\ Peter Blanck*»
}

This article explores factors important in the study and examination of corporate culture and change. The particular focus is on the technological methods used to conduct a study of accessible technology and corporate culture at Microsoft Corporation. Reasons for particular approaches are explained. Advantages and challenges of emerging technologies that store and retrieve information in the study of corporate culture are reviewed. Copyright (C) 2005 John Wiley \& Sons, Ltd.

\section{INTRODUCTION}

The Law, Health Policy \& Disability Center (LHPDC) undertook a study of the corporate culture of a large corporation, Microsoft (MS), to understand better how persons with disabilities are included in the workforce and how accessible software and hardware products evolve in the information technology (IT) industry (see Sandler \& Blanck, 2005). Implications for the study of corporate culture as well as for the conduct of research and methods for studying IT or IT-using companies are discussed herein. The study of IT and IT-using organizations presents challenges that require development of new approaches in data collection and analysis. Data are available in new and evolving electronic formats and media, which require

\footnotetext{
*Correspondence to: Peter Blanck, Law, Health Policy and Disability Center, University of Iowa College of Law, Iowa City, IA 52242, U.S.A. E-mail: peter-blanck@uiowa.edu

${ }^{\dagger}$ Director of Technology, Law, Health Policy and Disability Center (LHPDC), University of Iowa College of Law; Ph.D., University of Iowa.

${ }^{\ddagger}$ Associate Director, LHPDC, University of Iowa College of Law; J.D., University of Iowa.

${ }^{\S}$ Charles M. and Marion Kierscht Professor of Law, and Professor of Public Health and of Psychology at the University of Iowa; Director LHPDC; Ph.D., Harvard University; J.D., Stanford Law School.

The program of research described herein is supported, in part, by grants from the National Institute on Disability and Rehabilitation Research, U.S. Department of Education, Microsoft Corporation, The University of Iowa College of Law Foundation, and the Great Plains ADA and IT Center. The views herein reflect only those of the authors and not of any funding agency or any other entity.
}

Contract/grant sponsors: National Institute on Disability and Rehabilitation Research; U.S. Department of Education; Microsoft Corporation; The University of Iowa College of Law Foundation; Great Plains ADA and IT Center. 
understanding of why organizational cultures adopt these technologies and how technologies interact with these cultures. Further, these formats and media require new and evolving research skills and methods as well as tools to collect, manage, and examine such data.

LHPDC examined Microsoft Corporation's efforts to enhance diversity, specifically toward inclusion of persons with disabilities in its workforce and efforts to improve product and service accessibility for persons with disabilities for both its workforce and its customers. The focus of this case study of Microsoft is the corporate culture, leadership, and dynamics that drive MS. Law, regulatory compliance, and social policy are also important factors to be examined. The public at large and disability advocates influence corporate behavior and culture related to persons with disabilities. Technology — both at MS and that of other IT companies, whose technologies compete against and interact with MS products - plays a role.

The process of collecting, managing, and analyzing data collected during the study, using relatively new workplace technologies, such as e-mail, presentation software, publishing software, and the World Wide Web browsers, revealed issues related to emerging technologies and their effect on research of corporate culture. This article outlines some of the issues encountered during this research, how they relate to research on corporate culture and people with disabilities, and how they may affect future studies.

In this introduction we discuss some of the reasons to study organizations and culture. Then, we discuss the study of IT organizations. Finally, we explain the reasons for the selection of Microsoft as a target of study. In the second section, we discuss methods of studying an IT organization's corporate culture. In the third section, we illustrate methods of data collection, management, and analysis as applied to the study of corporate culture at Microsoft. In the final section, we highlight issues and discuss likely future technologies related to the study of corporate culture, disability, and use of information technology in such studies.

\section{Corporate Culture}

Much literature on corporate culture bases its conceptions of corporate or organizational culture on Schein's seminal writings (e.g. Schein, 1985). Corporate culture is usually defined as the system of assumptions generally agreed upon in the organization. This system of assumptions is ingrained in an established organization and has become invisible and inarticulable by members of the organization. Further, these assumptions are generally viewed as having evolved from the philosophies of the founding leaders and an interaction with the needs of the organization for survival in its environment. A major reason for having a corporate culture is that it motivates people to change their behavior in line with corporate necessity without a direct tie to financial compensation. Although culture itself may be difficult to research directly, the artifacts of the culture may be studied to provide clues to the assumptions and belief system in place. These artifacts include corporate rules, philosophies, shared values, norms, and patterns in the physical manifestations of the organization as well as in the behavior of its members (Lazear, 1995; Schein, 1985, 1986). 


\section{Why Study Organizations and Corporate Culture?}

The study of corporate culture has been conducted as a means to explore the forces that determine how an organization and its personnel think about, understand, interpret, and act on their methods of operation, strategies, and goals (Schein, 1999). Organizations are "fundamental building blocks of modern society and the basic vehicles through which collective action occurs" (Aldrich, 1999, p. 5). With organizations as vehicles for social action, it is critical to understand how they act, and perhaps more importantly why they act. Until understanding is achieved of how and why people and organizations act, change will be difficult. Perhaps it is not possible to direct change or test hypotheses in corporate culture through traditional research, but as Schein notes, "Good description and analysis is a stage of science that is much needed" (p. xvi).

Good description and analysis is required of the methods of examination of corporate culture and the particular findings of study related to the employment of people with disabilities. Improvement in employment status of persons with disabilities is necessary, as demonstrated by the high unemployment rate of persons with disabilities (Blanck, Schur, Kruse, Schwochau, \& Song, 2003; National Organization on Disability, 2000). What role corporate culture plays currently or will play in the future in that change has yet to be determined.

Little has been studied in the area of corporate culture around disability issues. Some diversity research includes disability as a category of interest, but the focus remains on gender, race, and sexual orientation (Knowling, 2003; ITAA, 2003). ${ }^{1}$ Most existing research on disability has focused on supervisor and coworker attitudes and their effects on employees with disabilities (Blanck \& Marti, 1997). Research has been performed on factors that influence attitudes, which include stereotypes, discomfort with being around people with disabilities, communication difficulties, personality, and prior experience with people with disabilities. Effects of supervisor and coworker attitudes include research on performance expectations, performance evaluations, desire to have coworkers with disabilities, and hiring into positions of responsibility (Schur, Kruse, \& Blanck, 2005). However, these studies focus on what may be artifacts of corporate culture, or of the culture at large. Although their importance should not be underestimated, especially since artifacts help create an atmosphere that reinforces or changes the culture, the information derived from such research may not provide reliable insight into the assumptions that make up the cultures that support these behaviors. A better understanding of such cultures may help expose ways to improve the employment status and the lives of people with disabilities in a way supported within the cultures.

Research has been undertaken by the U.S. General Accounting Office (2002a) on the effects of economic incentives on corporate behavior and employment of persons with disabilities, including tax incentives. Other economic incentives and policy, particularly social security income guidelines and work incentives that apply to individuals, have been examined in GAO research reports (U.S. General Accounting Office, 1996, 1997, 1998a, 1998b, 2001, 2002b).

\footnotetext{
${ }^{1}$ For examples of how disability has not been addressed in diversity literature, see Cross and White (1996), where only pages 227 and 241 mention disability; Hayles and Russell (1997), especially Figure 62 (p. 87), which omits disability entirely; and Prasad, Mills, Elmes, and Prasad (1997).
} 
Other research has studied corporate efforts towards regulatory compliance in the area of civil rights. Civil rights laws pertaining to people with disabilities include the Americans with Disabilities Act (ADA) and the Rehabilitation Act of 1973 (Rehab Act) as amended. As in diversity research, emphasis on civil rights compliance generally has not focused on disability but on race, gender, or sexual orientation and the state and federal laws pertaining to such protected status, including the Civil Rights Act of 1963 and the Equal Employment Opportunity Act (Aldrich, 1999; Edelman, 1992). Employee response to corporate implementation of law and regulation has also been examined recently, and does include the ADA (Fuller, Edelman, \& Matusik, 2000). Both economic incentives and regulatory compliance have implications for corporate culture as well as, directly and indirectly, the employment rates of people with disabilities.

Knowling (2003) suggests that change relies not on law or external incentives, but rather on actions in the boardroom, regardless of external influences, which mandate increased diversity. At-risk compensation-for example, pay tied to performance and specific goals - may be tied to diversity by looking at position and pay to ensure that diversity and equity are achieved. Determining who has responsibility to implement diversity and then understanding the systems of rewarding or penalizing the responsible parties may be of interest in future study. It is possible to reward individual performance on the basis of the ability to create teams (Schein, 2000). The diversity of such teams, which include people with disabilities, might be one variable in evaluating a leader's ability to drive change. Measuring the creation of diverse environments by such leadership has relevance to driving change (Gilbert \& Ivancevich, 2000; Kochan et al., 2003; Schur et al., 2005).

\section{Why Study Large Organizations?}

Large, publicly traded corporations constitute less than one percent of organizations (Aldrich, 1999). Only 484 firms employed more than 10,000 employees in 1994 (Aldrich, 1999). Yet, although only two percent of firms in the United State have more than 100 employees, more than $60 \%$ of all employees are employed by such firms (Aldrich, 1999). Large employers then are the minority of organizations, but employ a majority of employees. Employers with from 20 to 99 employees constitute nine percent of employers, while small companies and organizations employing from 1 to 19 employees constitute 89\% of employers (Aldrich, 1999). Data from 1998 indicate that $72.1 \%$ of employees worked in firms with 25 or more employees (Headd, 2000). In sum, organizations with more than 19 employees constituted $12 \%$ of organizations, but employed well over $72 \%$ of employees. These organizations are above the 15-employee threshold for coverage by the non-discrimination provisions of the ADA and other civil rights laws. Focused study of large corporations has the potential to affect the largest portion of the workforce.

Another reason to study large corporations is that the largest nine percent of corporations control $97 \%$ of corporate assets (Aldrich, 1999). With greater resources, these employers may be more likely to bear needed initial costs and then derive likely benefits from accommodating workers with disabilities. Much has been discussed on the positive economic impact to firms when they hire persons with disabilities (Blanck et al., 2003b). 
Finally, because many large corporations are publicly traded, more information is available about such firms, for instance, in the form of reports filed with various regulatory agencies and in extensive news or analyst coverage (Aldrich, 1999). With more data, understanding such firms becomes easier, though as Silverstein and others caution, analysts should understand the limitations of data collected for a single purpose (to examine public policy in other areas) to understand the implications of using the data for another purpose (Silverstein, Julnes, \& Nolan, 2005). Fewer data are available about small firms, but sources include the Small Business Administration, the Internal Revenue Service, the Department of Labor, and the Census Bureau (Aldrich, 1999). Although study of corporate culture through limited collected data on small firms may be problematic, when aggregated across firms or industries these data may be useful.

Large employers also are likely to be cognizant of and responsive to relevant federal anti-discrimination law (Edelman, 1990, as cited by Aldrich, 1999). They often establish offices for anti-discrimination activities, including ADA compliance, and use human resource systems to manage employees (Edelman, 1999). Data may be available to researchers from either regulatory reporting (individually from the company, or aggregated from the federal agency), or from internal data sources used for compliance or for human resource management. Responses to regulation are both internal to an organization and important to the persona the organization presents externally (Edelman, 1990, 1992; Edelman, Uggen, \& Erlanger, 1999; Fuller et al., 2000).

\section{Why Study Information Technology Organizations?}

Information technology companies such as Microsoft provide opportunities for people with disabilities either as employees or contractors, or through products and services they generate. Such companies and technologies are the focus of demonstration projects and studies researching barriers to or facilitators of employment (Blanck, Ritchie, Schmeling, \& Klein, 2003; Schartz, Schartz, \& Blanck, 2002). Because many positions in IT companies, such as software programmers, writers, and graphic designers, not to mention white-collar management positions common to most other industries, do not require significant physical effort, and instead require intellectual skills, people with physical disabilities may have a more level playing field for employment.

Besides IT companies, large, non-IT companies are significant users of IT, and IT-based jobs, as well as accessible products and services, and provide significant employment opportunities. IT may enable new forms of work, including telework, which previously were unknown, or contingent work and temporary work, often relying on interchangeable IT work skills (Kruse, 2001; Kruse \& Hyland, unpublished manuscript; Schur, 2002, 2003). Such work arrangements are beneficial to workers with disabilities when transportation barriers exist or when flexible work is a desirable option. In the future, these kinds of generalized IT skills may be needed in greater numbers as IT becomes integrated into corporate infrastructures more as a utility (Carr, 2003).

A key to these technologies, however, is that the IT systems must be accessible to persons with disabilities if they are to be used by them. The National Institute on 
Disability and Rehabilitation Research (NIDRR) funds centers, including an extensive program of Rehabilitation Research and Training Centers (RRTC), Rehabilitation Engineering Research Centers (RERC), and Disability and Rehabilitation Research Projects, many of which are researching and developing these technologies and examining their uses for employment. ${ }^{2}$

Technology developed for and used by persons with disabilities have broader impacts for the workforce and can be adopted company-wide when they have advantages for productivity. Universal tools once considered assistive technology, such as screen readers, spell checkers, voice recognition software, and the like, have been implemented in companies, showing improved productivity for all workers (Blanck, 1996).

\section{Why Microsoft?}

The aforementioned reasons for studying large corporations and IT, as well as the wide array of products and services that Microsoft provides, makes MS a company of interest. It is a large employer, modeled by many corporations, about which a great deal of public information is available, and it produces and uses accessible IT in its business.

Microsoft played a prominent role in the 1990s not only in software/technology development, but also in the U.S. economy. On June 30, 1995, MS employed 17,801 people and had net revenues of $\$ 6.08$ billion (Microsoft, 2004a). On June 30,2004 , MS had increased its employment to 57,086 and its net revenues to $\$ 36.84$ billion (Microsoft, 2004a). Microsoft is one of the largest companies in the IT industry, and its products are used throughout the U.S. economy. The company is so successful in desktop software that it is considered to have a dominant position in the United States on personal computer operating systems with its flagship product, Windows. Ranked 72 in the Fortune 500 in 2002, the only pure IT companies higher on the list were IBM, Hewlett-Packard, Compaq, Dell, Motorola, and Intel (Fortune, 2002a). On the Fortune computer software industry rankings, MS is first with revenues more than twice as great as its nearest competitor, Oracle (Fortune, 2002b).

\section{This Study}

The current study investigated internal subcultures at MS and how they related to external disability stakeholder groups during the decade of the 1990s (Sandler \& Blanck, 2005). The researchers explored the following themes: (1) how employee personal experience, corporate leadership, and stakeholder feedback affected product development related to people with disabilities, and (2) how the company's development of accessible technology and software changed (a) internal employee productivity, (b) employee retention and career advancement, and (c) external product demand and revenue.

\footnotetext{
${ }^{2}$ For a list of projects funded by NIDRR and the areas of research focus for each Center and project, see U.S. Department of Education (n.d.).
} 
The program of research included observations, interviews, and review of public and private archival data. LHPDC conducted interviews with more than 40 people inside and outside MS, one on one, or in groups. Observations of meetings and presentations occurred during two onsite visits to Microsoft's Redmond campus. Web pages, books, journal articles, and news stories were collected and examined. MS provided thousands of internal documents and electronic (computer) files for review.

\section{Technology and Organizational Change}

Ultimately, a disability research agenda will include a goal to learn about how corporate change improves the lives of people with disabilities. Current research is inconclusive about whether emerging technologies create change in organizations. Predictions that computers will facilitate communications and more widely distribute the decision-making base go back as far as 1958 (Leavitt \& Whistler, 1958, cited by Boddy \& Gunson, 1996). Empirical studies show some structural changes in organizations but the cause of the changes is indeterminate. Are the changes caused by the technology, or was the new technology implemented as an expression of changes in the work culture? Were the changes in both areas actually caused by an external factor? Are changes even noticeable as they occur or are they observable only in the aggregate over time (Meyerson, 2001)?

Many have predicted a flattening of organizational structure with less need for middle management. Traditionally, middle management has been in place to interpret upper management directives to make decisions at the local level and to compile local data to report to upper management. Electronic communication has made more information from upper management available to lower-level managers so they are better able to make local decisions, and in the other direction local information is more easily and quickly transmitted to upper management. However, rather than seeing a reduction of middle management in corporations, we have seen an increase as technology enhances information flow and organization (Attewell, 1994, cited by Brown \& Duguid, 2000).

A great deal of data may be made available from a large IT firm. Collecting, analyzing, and understanding that information for clues to the corporate culture, particularly as applied to persons with disabilities, present new challenges to social science researchers. How the data are created and disseminated by employees using emerging technologies creates new opportunities for, and barriers to, data collection, management, analysis, and dissemination of disability research. The present article discusses the approaches taken by the LHPDC and how those approaches might be expanded upon, changed, or applied in the study of corporate culture.

\section{METHODS OF STUDYING CORPORATE CULTURE}

One problem in conducting research on corporate culture lies in the difference between the organization's public persona and what actually takes place daily in the workplace. The public persona may be dominated by public relations, marketing, and legal forces, which demand fairness and positive human relations. The dynamics of the corporation behind the public persona, the human interactions 
that organize, motivate, and communicate among individuals in the organization to get work done, may demand fairness and positive human relations, but these processes may not be accurately reflected in the organization's public persona.

As a way to cope with and thrive in an environment that includes competition, human interactions, and corporate survival, an organization invents, develops, and discovers a pattern of assumptions, explicit and implicit, understood by most employees and which govern day-to-day operations of the organization. These assumptions adapt to changing workplace demands and are taught to new employees as the correct way to perceive, think, and feel about the workplace. Leadership creates and manages the organizational culture, as distinct from managing and administering the organization (Schein, 1985). Leadership manages corporate culture predominantly through influencing shared practices (Hofstede, 1991).

\section{Subcultures}

In addition to the dominant culture, an organization may have numerous subcultures (Schein, 1985). At MS, for instance, the various product groups, the divisions of the company, the managers, the business leadership team, or the accessible technologies group (ATG) may represent different subcultures. Employee-affinity groups may represent subcultures of interest. Each interacts with the other subgroups, alternatively dominated by, influencing, and forming the corporate culture at MS. Identifying and examining the cultures and subcultures of interest in relation to the dominant culture are goals of studying corporate culture. Organizations and perhaps their subgroups are "goal-directed, boundary maintaining and socially constructed systems of human activity" (Aldrich, 1999, p. 2). Understanding these systems requires identifying and examining the goals, boundaries, and activities of the organizations and relating them to the contexts of the society in which they reside.

Identifying the groups of interest was the first challenge. At MS, the employee affinity groups are easy to identify - they are featured prominently on the company's diversity website (Microsoft, 2004b). There are currently 21 groups listed, of which three are related to disability: the Visually Impaired Persons in MS (MSVIP), the Deaf and Hard of Hearing group, and the Attention Deficit Disorder (ADD) group. Others are based on ethnicity, geographic origin, parental status, gender, and sexual orientation. According to MS, these self-organized groups "provide support and networking opportunities such as mentoring, recruiting, working in the community, career development, and assisting in other activities that promote cultural awareness" (Microsoft, 2004d). These represent employee efforts, sponsored by the company, to include diversity in the corporate culture of MS.

The corporation has subgroups of employees that directly impact the employment of persons with disabilities as well, including the diversity advisory committee, the accessible technologies group (ATG), and the ADA accommodations committee. Other groups who make business decisions that impact people with disabilities in the company include the human resource teams, the business leadership team, and product or program managers. Still other groups impact the lives of persons with disabilities through their product development, and include the Windows group, the Office group (which itself includes the Word group, Excel group, and the 
like), the Encarta group, and others. While each has worked with ATG-whose mission is in part to provide information to developers at MS about the disability community and its needs, on product and code development-and while each has worked with third-party assistive technology vendors, each has responsibility for its own product development activities.

Identifying each group and the role it plays was a major challenge to the research, as was discovering the interactions among the groups. Even more challenging was identifying communities of practice, the people included in those communities, and how these individuals negotiated their identities and roles in various communities within and outside the organization. A program manager from ATG may officially and physically be relocated to another group, such as MSN (again as a program manager), perform many of the same activities as he did in ATG, and maintain many of the same professional connections.

Decisions are made within and among these groups that reflect the corporate culture of the organization and the cultural backgrounds of the groups and the individuals in each group. These decisions impact the corporation, the employees, and the customers in different respects, and may be examined by researchers. Such subcultures may work together or be in conflict, depending on the goals and responsibilities of each within the company (Schein, 2000).

\section{Clinical Field Research}

For beneficial relationships between the participants and the researchers to emerge, a clinical research model may be effective (Schein, 2000). Clinical-field-research approaches to studying organizational behavior are effective at understanding corporate culture and how it affects people with disabilities (Blanck \& Turner, 1987). This approach is designed to capture a complete picture of an organizational system, through immersion in the system being studied, with recognition of the ways that researchers influence the organization as part of the process of doing the research. The method is not designed necessarily to test research hypotheses, but rather to build theory and understanding of an organization. Interviewing and observation are emphasized in this method. Basic understanding of new organizations or roles in organizations is a goal, and focus is on function of the organization. Immersion in the organization and observation of the organization leads the researchers to a better understanding of other appropriate research methods and goals. Such immersion and observation may be the only viable way to understand new or small organizations, where data are not yet available from traditional sources of information on corporations (Aldrich, 1999), and these methods probably are the only way to learn about an organization's belief system on which the culture is built.

Narratives from informants can be important for understanding organizations (Czarniawska, 1997), and in this study narratives from MS insiders and outsiders were critical. Open-ended interviews provided opportunities for individuals to describe through narrative what they have seen in MS as well as the meanings they ascribe to the events. Individuals may focus on the actions within and outside the boundaries of the system of rules.

Among informants include those who advocate change within the system. Meyerson (2001) describes "tempered radicals... organizational insiders who 
contribute and succeed in their jobs. At the same time, they are treated as outsiders because they represent ideals or agendas that are somehow at odds with the dominant culture" (p. 5). Tempered radicals might undertake a spectrum of activity to effect change in an organization. The spectrum ranges from quiet resistance through organizing collective action. Policies that begin as individual imperatives (e.g. not scheduling meetings after 5:00 P.M., or implementing formal flex-time arrangements widely after first using informal flex-time for an individual) may become adopted by working groups as they conform to requests from individuals. Such individuals ("evangelists") were encountered throughout the Microsoft study (Sandler \& Blanck, 2005). Many of their actions relate in particular to product development and implementation of accessibility features. These types of individuals are key informants when examining change driven by individuals who understand the corporate culture in which they reside, though because of their moderately radical actions they may not provide a prescription for further or widespread corporate change.

One way of systematizing and understanding these data is through demographic study of organizations including the way they "develop and change over time through processes of organizational founding, growth, decline, transformation, and mortality" (Carroll \& Hannan, 2000, p. xx; also see Aldrich, 1999). In many cases, data from the early days of a corporation through its evolution may not be available because of the extensive lifespan of the organization. In the case of MS, the organization has a comparatively short history and many of the founders are active, though not widely available to researchers.

MS, and particularly the accessible technologies group (ATG), the group at Microsoft explicitly responsible for disseminating information about accessible technologies to other product groups, lent themselves to this approach for study because the group was founded, grew, and several times transformed during the period of interest, but the approach was not without difficulties. The organizational chart, though only an overview, was obsolete as soon as it was received, and updates were soon superseded, and never provided in complete form again (Sandler \& Blanck, 2005).

Study has been undertaken of MS because of its rapid evolution and the prominent role of its products. Biographies of leaders are available. Leaders and former leaders grant interviews. Each of these individuals may be an agent responsible for driving change in employment policy or product development. While current or contemporaneous study is valuable, and in some cases available, the people who were on the ground when the changes happened also may have a larger perspective and be able to put events in context several years later. When current interviews are combined with documents from the period under study, the sum of the information is more useful than either separately. In an IT company, such documents may be widely available than in other companies because of the nature of the technology and the ease of archiving.

\section{Triangulation}

Triangulation of field research approaches is used to validate and define the limitations and generalizability of the findings of these immersive methods (Schur 
et al., 2005). Other qualitative methods, as well as quantitative methods, may be used to review interviews, onsite observation, surveys, and archived materials. Where this method uses an etic perspective, an outsider's view of the culture, such a combination of research approaches strengthens and broadens the results of a study on organizational culture (Mohan, 1993).

Researchers triangulating data on corporate culture also may examine behavioral regularities, norms, espoused values, philosophy, rules (including those needed for getting along in the organization), and climate (Schein, 1985) for consistent themes in values as distinct from those in the environment. Artifacts of an organization include the organizational structure, its method of disseminating information, and how it carries out command and control. In addition, particular artifacts, such as mission statements, charters, publicly stated goals, and marketing objectives, inform research, as well as stories that circulate the workplace, which include myths and legends (Schein, 1985). Such products of corporate culture may be identified and examined through interviews with current and former employees, business partners, and others; through review of public and private documents; and through review of others' research.

Examples of such artifacts are prominent in IT companies with extensive websites such as Microsoft's. Diversity statements, accessibility policies and practices, recruitment efforts, and public relations materials are sources of data available publicly. When well organized by a corporation, they are relatively easy for researchers to analyze but represent only the public face of the organization. Deeper inquiry is possible if the researcher and the organization interact directly and build a relationship that incorporates trust and reward for both parties to the project (Schein, 2000). The case study approach used in the MS study allowed this kind of deeper inquiry.

\section{Emerging Technologies}

Archived materials that inform researchers about the culture underlying the organization's public persona may include personal documents, such as letters, journals, logs, autobiographies, and scrapbooks, as well as official documents, such as memos, minutes from meetings, policy documents, proposals, personal records, newsletters, and news releases (Bogdan \& Biklen, 1992). In the past, these data have been archived on paper, although audiotape, photographs, and videotape have been used as means for archiving data. Frequently, too, interviews recorded on audioand videotape are transcribed to paper. However, emerging technologies have opened data to new forms and media, such as e-mail, instant messages, digital text and publishing documents, calendars, databases, presentations, and digital audio and video. When these are available electronically, often the possibility exists for using other emerging technologies such as search engines to find particular items of interest within the large volume of data available to the researcher.

Today, work product of, and information flow in, IT corporations tend to be in electronic form because of the convergence of telecommunications and computer technologies into network systems (Boddy \& Gunson, 1996). This digitizing of work product has business benefits for improving processes within a corporation. One benefit of interest is that it may provide greater flexibility for accommodating people 
with sensory and cognitive disabilities. For example, screen readers convert text to speech, which minimizes visual limitations. Voice recognition conversely converts speech to text. Electronic text can be provided in alternative formats, including large text or Braille. Many other alternative methods for data input and output are available, and may be customized to the needs of individuals and their environments.

These technologies provide new opportunities and challenges for researchers. Documents such as e-mails and policy papers are distributed widely. Large numbers of documents, including their many versions, can be stored easily in different locations. E-mail can be a dominant form of communication, which can take on a different tone (often less formal) and purpose (e.g., sending attachments) from traditional letters or phone conversations, especially in business. Attachments to email open up widely distributed information to many forms and formats. Publications that previously may have been distributed on paper can be distributed in other, electronic formats, such as Adobe Acrobat, PageMaker, Microsoft Publisher, Microsoft Word, WordPerfect, and HTML. Instant or text messaging (IM) facilitates less formal, instantaneous communications, where an entire conversation might be saved.

This last point has led to product developments that automatically archive such instant messaging communications to comply with regulatory requirements, such as in the financial services industry as mandated by U.S. Securities and Exchange Commission (SEC) and NASD rules, as well as requirements of the Sarbanes-Oxley Act of 2002. More regulations from these and other authorities will follow, mandating similar treatment of communications through new technologies as they are developed. IBM, for instance, touts its product for Health Insurance Portability and Accountability Act (HIPAA) compliance. Undoubtedly, at some point IM client logs will be used in the study of corporate culture because they will be part of the business records of any corporation that uses the technology.

Multimedia formats are common, producing data for presentations (PowerPoint), graphics (GIF and JPEG), and audio and video (QuickTime, Windows Media Player, and Real Player). Further, information that may be distributed through one medium, such as paper or videotape, might be converted to a digitized medium and disseminated on a wider scale. Information in any given multimedia format might be converted to another multimedia format or to other media. For instance, a PowerPoint graphic presentation might be converted to a plain text outline; a drawing or photo might have an alternative description that describes or interprets the visual presentation.

\section{Data and Document Management}

New challenges confront researchers with emerging technologies. With large numbers of digital documents created and stored in multiple versions and in multiple locations (including regular archived back-ups of entire hard drives), a critical problem for the corporation and the researcher is data management. Locating and manipulation of data requires use of search technologies, metadata (data about the data), database technologies, and means to share data (Chin, 2001). One solution to data management is the use of databases, which ideally provides the 
correct information to the people who need it when they request it at an acceptable cost to the organization (Atre, 1998). For researchers, organizing data into databases that access, organize, and otherwise manipulate the data in useful ways is one challenge.

To provide some way of systematizing documents, information about the documents - metadata - is created and organized into databases. Metadata can be contained in the documents themselves or created by those who need to manage the documents. This mechanism is not new, having been used in traditional library card catalogs for some time. However, digital documents provide metadata more easily. The document type, including form or format (e.g. Word document, Excel spreadsheet), structure, and information about content are forms of metadata (Fisher \& Gangolly, 2001). While the form or format can be part of the document (e.g.. the file name that ends with . $d o c$ self-describes as a Word file or . $x l s$ as an Excel file), the information describing structure and information about the content of the document must be coded manually into a database to be useful (Fisher \& Gangolly, 2001). The content itself is the data; the information about the content, used to organize the information, describe it, and retrieve it, is the metadata. In the current study, the documents provided by Microsoft were organized by the research team into a database by file type using this kind of self-contained metadata as one organizing principle.

The use of metadata in databases allows information seekers to search for documents, such as by author name, date published, file name, or whatever metadata has been used as an organizing factor in the document management system. Such metadata are useful for more than retrieval as well. Tyler and his collaborators, employees of HP Labs, used metadata - specifically the "to" and "from" lines of e-mails - to discover the structure of communities of practice (Tyler, Wilkinson, \& Huberman, 2003). They examined leadership and collaboration within an organization through the use of IT and found that IT enhanced their ability to identify these communities, particularly because the process could be automated.

In the present study, the research team manually coded author and audience information from documents provided by MS when that information was available. The availability of automatic coding enhances such research because of its speed but is not possible where such metadata is not part of the document in a standardized form. E-mail may present the best example of ease of automation, as in Tyler et al. (2003), while Word or PowerPoint documents allow author information to be gleaned automatically but not audience information. Each format for data will have particular idiosyncrasies to be evaluated and programmed if automated tools are applied.

\section{Ad Hoc Digital Documents}

Although databases using metadata allow fast categorizing, search, and retrieval of digital documents, some document artifacts generated by an organization are not as easy to manage. These are ad hoc digital documents, documents created as needed and stored unsystematically outside any formal document management system (Murphy, 2001). Such documents are created and proliferated by information workers in every field. Users may create complex documents, which are capable of 
including metadata within the files (e.g. in the properties box of Microsoft Office documents and in the file system's file attributes), but may not use those functions. It is up to the researcher to fill in the gaps where possible and to use the limited information available by default in the programs used to generate the documents (Murphy, 2001). Examples of the metadata included in the MS files and that were coded by the researchers are presented in Figures 1 and 2 .

Besides locating and managing such documents, ad hoc digital documents create a further difficulty for researchers. Within organizations, content from ad hoc digital documents is shared and reused extensively, where different workers copy, repackage, and reuse material for different occasions and different audiences (Murphy, 2001). This is a challenge for researchers trying to trace the genesis of an idea or procedure unless good metadata are available. For instance, in our study, we reviewed documents written, re-written, presented, and altered over multiple years with the same or similar information used for different events, purposes, and audiences. Some documents used the "track changes" feature of MS Word, which showed multiple authors offering multiple feedback on documents. Tracking the changes and ordering of these documents was possible through data within the content of the document and through document properties boxes. Others used the "comment" feature, which is another way for people to give feedback on the document, but without altering the content of the document as the track changes feature does.

Additional challenges arise from software features that allow users to set how they view feedback, and as these settings change through different versions of the software. Some settings in Word show changes or comments while others hide them. This can vary depending on whether the documents are reviewed on screen or printed. It can be set to show only when the mouse cursor hovers over the change or comment, for example. Careful examination by researchers may be necessary to capture this detail when it is present, and search technology may not find these comments or changes.

The study of ad hoc digital documents is an imperfect process at best, and often it is not discernable what document represents the first or last in a series, or what final version is adopted. Murphy also details traditional and emerging roles for metadata. Traditional roles include search and retrieval, evidence, record retention, and others, while emerging roles include interpretation and re-use, organizational memory, persuasion and increased visibility, and allocation of resources. Each is important to researchers examining corporate culture through artifacts, especially digital artifacts of new information-age economy corporations (Murphy, 2001).

Further, ad hoc digital documents may be a rich source of information about corporate culture and people with disabilities. Where systematized documents, such as organizational forms and mass communications, or even forms of e-mail communications, can be considered public documents, in the sense that they may be transferred or forwarded within and outside the organization, in contrast, ad hoc documents may be intended for personal use only and may reside on a single hard drive. Thus, information may be candid and less encumbered with corporatesponsored language. In addition, many people with disabilities find unconventional ways to function within a system when the system is not flexible enough to allow them to work efficiently. For example, someone using a screen reader may prefer to convert word-processed or Web-based documents into plain text files before reading them to avoid distracting formatting information. 


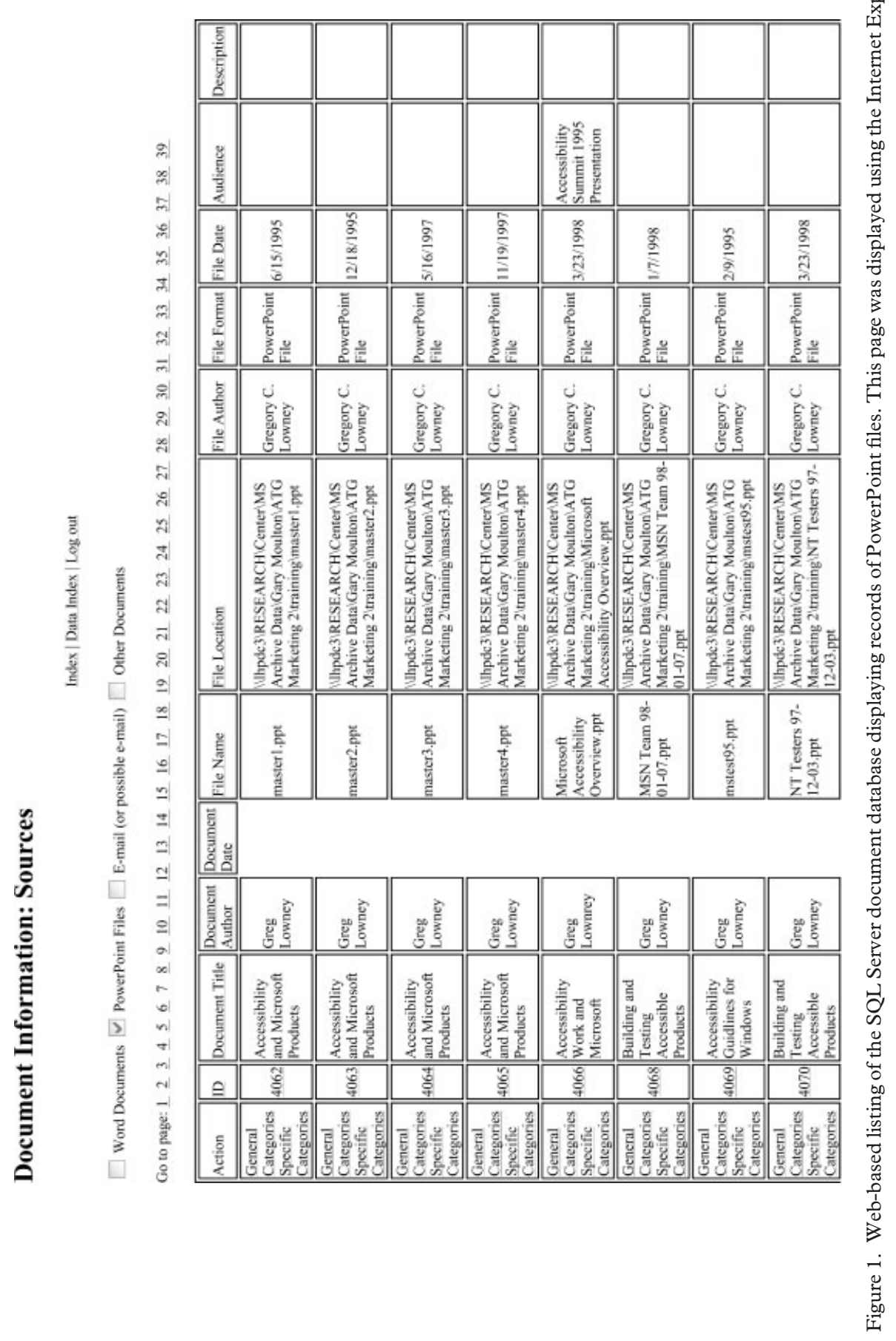




\section{Document Information: General}

Index | Data Index | Data Sources | Specific Data $\mid$ Log out

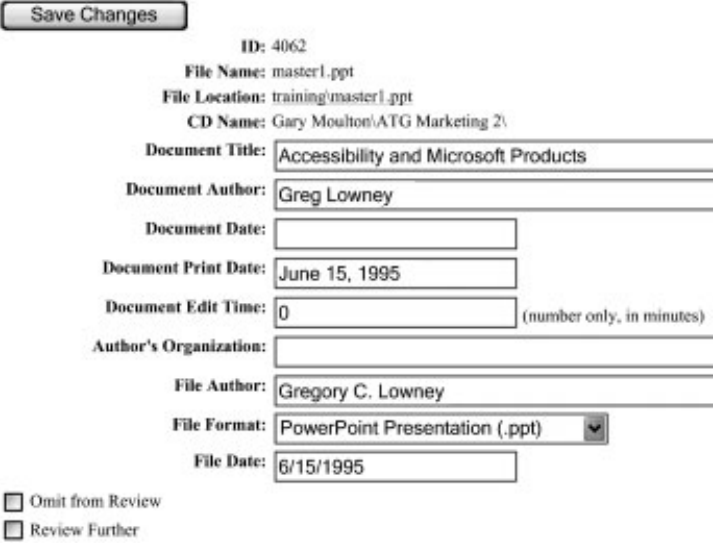

Date last changed. 11/16/2001 12:25:00 PM By mmayo

Figure 2. Coding page for basic information about research data documents.

\section{Emerging Technologies for Researchers}

Emerging technologies provide researchers with opportunities as well as challenges compared with more traditional data forms. Advantages include the ability to search the entire content of documents and organize materials by key word rather than manually re-reading each document. Collecting data electronically is often efficient. For example, an informant can simply copy and paste, drag and drop, or attach relevant documents rather than photocopying and mailing reams of paper. Disadvantages may include having to implement new forms of security, designing 
systems of data management, which affect management of a research project, and discerning the reliability and validity of data.

Some data may be found in public bulletin boards or listservs, which are archived and available. Use of these data, of course, implicates ethical issues (Brem, 2002). However, often a rich history of an organization and various stakeholder interests are available because of archives of public discussions that otherwise might be lost. Such archives present historical information that the company might not itself archive, or that other stakeholders think is particularly important to preserve and make available. These histories illustrate changes over time as opposed to snapshots of the present. Historical information and current snapshots have value to researchers and other stakeholders.

One caution is needed when research incorporates new technologies in data and data collection. As emphasized by Brown and Duguid (2000), theorists and researchers should avoid an "infocentric" view of corporate culture, where the dynamics of organizational change are viewed through the lens of information technology forces, rather than through an overarching social lens. As the stock market bubble at the end of the last century indicates, where investors speculated millions of dollars on start-up technology companies with no track record and a slim assurance of profitability, the myth of information can overpower a richer understanding of organizations and organizational dynamics. Brown and Duguid suggest that recent increases in middle management as noted above are a result of social forces, not technology. We remind ourselves that middle managers are more than just information processors. Although information flow and organization may be facilitated and changed by emerging technologies, the power to make decisions remains in the control of those who have traditionally made decisions. This suggests that, although researchers can inform their research about corporate culture using data produced by emerging technologies, organizational change may need to come from traditional change agents.

\section{METHODOLOGY}

\section{Data Collection}

To understand how to conduct research on a modern, high technology company, the LHPDC conducted preliminary research into the study of corporate culture, organizational behavior, and the types of information necessary to evaluate in the course of the study, much of which was discussed above. We first determined the types of information that we would need. We evaluated the ways this information could be gathered and determined methods we would use to organize, manipulate, and analyze the information. This required new methods of information management to be developed.

This study produced volumes of data, much of which was in electronic form. E-mail and telephone were the primary means of communicating with participants. E-mail was preferred by MS employees for daily and logistical communications while telephone was preferred for interviews. Data were collected through e-mail attachments from participants who were interviewed. Other data were received through a file transfer protocol (FTP) server set up for this study. An informant 
using the FTP server was allowed to log in to the server and upload the files to a specific area on the server. This was effective when informants used a fast connection to the Internet. This method was used for as much as 20 megabytes (MB) of data from one informant. To make file organization easier and to reduce upload time, the files were compressed (zip compression) by a participant into one $10 \mathrm{MB}$ file, and the upload took approximately 2-3 minutes.

Another participant had a significant amount of data-a compiled but unorganized archive of several years of activity in the corporation-which was copied to recordable CD-ROMs and "snail-mailed" to the researchers. This amounted to nine CD-ROMs, or 3.82 gigabytes of information. If sent via the Internet, either through attachments or FTP, this amount of information would have taken several hours to send, even over a broadband connection.

Documents received included official corporate documents, such as marketing materials, policy papers, and product specifications, and unofficial documents including e-mails, memos, letters, notes, internal training materials, and others. The format for e-mail attachments was usually a type of readable document, such as MS Word, Excel, or plain text (.txt) file. These attachments seldom exceeded 400 or 500 kilobytes $(\mathrm{kB})$ and would take a few seconds to upload on high speed (broadband) Internet connections.

\section{Interview Data}

Besides electronic documents sent from participants, this study generated its own electronic data. Thirty-four telephone interviews, most lasting about 90 minutes, were conducted, as well as several face-to-face interviews. Telephone interviews were transcribed into Microsoft Word documents. These documents included intentionally generated metadata about participants, about the transcriber, the copy editor, and the dates of the interviews.

If a participant mentioned a document during the interview, the interviewee was asked to send the document or asked where it could be obtained. These documents were used to triangulate information stated during the interview. Further, two site visits to MS resulted in several sets of notes by individuals recording participant observations from those visits. During the initial immersion into the study, Blanck, Sandler, Klein, and Murray visited MS. This served to acclimate them to the environment at MS, to set the bounds of the research, and to begin building the trust necessary to work with MS personnel (Sandler \& Blanck, 2005).

Blanck and Sandler visited a second time for a week and continued to meet with MS representatives and employees to establish the contours for the study. They met and interviewed people responsible for various aspects of Microsoft's corporate policy or software products. It was an information gathering trip, mapping out who was responsible for aspects the research team wanted to study. Face-to-face meetings were held to determine the course of study, discover the relevant documents and information available, and establish credibility between the researchers and the people with whom they would be corresponding in the future by telephone or e-mail.

Conducting interviews allowed the informants to narrate their perceptions of the organization and its conduct. Combining these narratives into a meta-narrative of the organization is useful to understanding the history as well as the present 
operation of the organization. These narratives provide insight into the operationalization of the corporate culture.

\section{Internet, Library Documents, and Resources}

As part of the process of triangulation of the data received, literature searches were conducted, which took researchers to the library and to the Web for information produced by third parties that supported or diverged from the assertions of the participants. Traditional library searches produced sources that discussed MS and corporate culture, which were reviewed in preparation for and during the study.

Beyond traditional library searches, additional keyword searches at online bookstores such as Amazon.com (www.amazon.com) and Barnes \& Noble.com (www.barnesandnoble.com) produced additional relevant book titles, usually easily and with richer metadata than library card-catalog interfaces. These search tools (actually sales tools) had additional metadata related to the books, including excerpts of books, tables of contents, complete indices of the books, reviews of the books from traditional book reviewers as well as readers, and cross-references to other books of interest based on the first book selected. Exploration of the use of these forms of metadata is warranted by researchers in the future.

Internet searches started with keyword searches using major free search engines, such as Google.com and NorthernLight.com. These searches produced results from a variety of sources, such as online periodicals, conference proceedings, newsgroups and bulletin boards, academic sites, government agencies, disability advocacy organizations, and personal Web pages. Researchers focused on retrieving information from periodicals, government agencies, and disability organizations, which often offered public documents that were well documented with references.

Data were found in newsgroups and bulletin boards dedicated to products, disability advocacy, or other related topics. These sources, which may have information archived as early as 1985, included discussions from people inside and outside Microsoft. A particular advantage of these sources is that the discussions had the tone of immediacy of the times. Some documents, such as letters exchanged among industry and government officials, had been posted to these boards, which allowed not only triangulation of the document contents, but also access to documents that had otherwise been unavailable. In one case, a compilation of letters that involve an exchange by the Massachusetts Commission for the Blind, the U.S. Department of Justice, Microsoft, and others was posted on Usenet, and archived, as well as reposted, on electronic bulletin boards (see, e.g., Mazrui, 1995, 1996).

As free public Internet sources with comprehensive information appeared exhausted, the research team turned to commercial Web-based solutions. One solution was a commercial search engine, BullsEye, ${ }^{3}$ which searched public websites based on keyword, similar to Google, ${ }^{4}$ but seemed to return more relevant pages based on a focused search. This engine was a useful tool after a researcher tried several engines, including demonstration versions of commercial ones. Additional commercial solutions included fee-based databases, like LexisNexis and Westlaw,

\footnotetext{
${ }^{3}$ Formerly available at http://www.intelliseek.com

${ }^{4}$ See http://www.google.com/
} 
that provide access to subscription-based periodicals, including newspapers and magazines, and allowed efficient searching of such sources.

\section{Barriers to Collecting Data from Emerging Technologies}

In the past, descriptive or qualitative research presented a number of barriers that prevented researchers from accumulating data. These barriers might include data not being accessible for a variety of reasons, such as confidentiality, lack of access to a gatekeeper, amount of time or effort needed to retrieve the data, and data having been destroyed (Blanck \& Turner, 1987). Similar reasons prevent researchers from acquiring new data types.

Reasons that some data, such as e-mails, memos, and other communications, could not be retrieved by interviewees reflected the dynamic nature of electronic information. A series of system crashes of one informant's computer had destroyed files that were not backed up. For another informant, data had been saved in a form that could be retrieved only by using an obsolete program no longer installed on the user's system. Some information had been archived on tapes and stored. Here, the main barrier would have been finding the person (another gatekeeper) in charge of the tapes, finding the correct tapes, and accessing the information (again, an older version of the software would have to be located) - an involved and uncertain process. In a corporate environment, where archived information can have negative consequences - because of changes in policy or to avoid wide publication of frank, private communications among employees-communications and other documents may systematically be destroyed (deleted) as a corporate policy.

Another significant barrier to the collection of new types of data is a result of the magnitude of available data. Informants sometimes expressed reluctance at having to go through several years of saved e-mails or documents to extract information relevant to the study. More significantly, when researchers were collecting Internetbased data, refining keyword searches on Internet search engines added significant work and time to the process. When several research assistants were doing the searches, even when trained at the same time, discretion and ingenuity in search terms was necessary, and these differed by person and search engine. For example, a search on the term "Microsoft" will produce tens of millions of hits on typical search engines; a search for "Microsoft accessibility" will return around 100,000 Web pages; and even the name of a Microsoft accessibility champion, "Greg Lowney," can produce over 5,000 hits. All researchers required time to learn successful search strategies on this topic.

Collecting data from respondents revealed another barrier, the technological experience of the informant. People who had experience using the technology LHPDC used for data collection had less trouble, but a variety of options had to be available from the research team to give informants the tools they knew how to use. Telephone conference calls, e-mail, and e-mail attachments were used most often. However, even technologically savvy participants could have difficulties. One individual from MS had to try uploading files to the FTP server three times (and succeeded only after calls to a technical support representative in the organization) because of problems with a pre-release version of an operating system on the computer used to upload the files. 
Table 1. Types of digital data collected for this study

\begin{tabular}{ll}
\hline File type & Number of files \\
\hline Readable text-based (total =2,858) & \\
Microsoft Word (.doc) & 1,583 \\
E-mail (.eml,.msg,.txt) & 168 \\
Text (.txt), rich text files (.rtf), WordPerfect (.wp) & 1,086 \\
Adobe Acrobat (.pdf) & 13 \\
Microsoft Publisher (.pub) & 8 \\
Microsoft PowerPoint (.ppt) & 395 \\
Web (.htm,.html,.asp) & 2,356 \\
Microsoft Excel (.xls) & 138 \\
Graphics (total=3,960) & \\
Compuserve GIF (.gif) & 2,832 \\
JPEG (.jpg) & 987 \\
Bitmapped (.bmp) & 94 \\
TIF (.tif) & 46 \\
Photoshop (.psd) & 1 \\
Sound (.wav,.mid,.ai) & 75 \\
Movie (.asf,.asx,.avi,.smi) & 157 \\
Other & 5,904 \\
Total files & 15,843 \\
\hline
\end{tabular}

Different types and formats of data were made available to researchers (see Table 1). E-mail was received as correspondence and archived data. Text documents constituted most of the usable information received. These text documents came in a variety of formats, including Word, plain text (.txt), WordPerfect, and rich text format. A similar format was publication format, such as Acrobat (.pdf) and Publisher documents. PowerPoint files were the most common of the multimedia formats. However, other multimedia files included graphics files (.jpg, .gif), sound files (.wav, .ai), and movies (.asf) in differing subformats (such as .asx or avi for movie files) for each type. Data also included many other types of file (e.g., .exe) that were associated with executable applications, for instance, a specific version of Internet Explorer and some software development kits.

This variety of formats created new barriers to accessing the content and other problems. For each file format, an application was required to view it. For example, MS Word was used for Word, rich text, and plain text format files. A graphics viewing program was needed for graphics files. However, where many formats can be viewed by a variety of applications (e.g., a Web browser can view most graphics files), Acrobat and Publisher files had to be viewed using proprietary Adobe and Microsoft applications (Acrobat or Acrobat Reader and Microsoft Publisher). This presents difficulty for researchers who do not have the appropriate applications, but more importantly this issue will grow complex in the future as applications or file formats become obsolete.

Other applications were needed to manage these files, including a database to keep track of files and to classify documents, and search engines to locate files based on different search criteria. The need for applications to view files as well as manage them had associated costs. The first cost was the direct cost for each application. Where some applications, such as graphics viewers, Acrobat Reader, plain text viewers, and media players (e.g., Windows Media Player) are free to download and widely available, other applications, such as MS Office, WordPerfect, and SQL Server, can be expensive. More expensive in some cases are the skills needed to use 
these applications. Applications such as Publisher and the database applications required skills that most people do not have, so someone with the skill set had to be found or someone in the research group had to learn them.

\section{Data Management and Security}

In this study, researchers were required to sign a nondisclosure agreement (NDA) with Microsoft. The agreement essentially restricted communication of nonpublic Microsoft information to those who held similar agreements until the company cleared information for dissemination. Because LHPDC did not have a pre-existing NDA, the agreement is governed by the terms in the contractual agreement, which requires that the researchers not disclose "Microsoft confidential" information, primarily information involving unreleased products, marketing information, or business strategies. Beyond the nondisclosure agreement, confidentiality was needed as a conventional way to elicit frank, detailed data from informants.

We treated as confidential all data provided by MS unless the data were available publicly on the MS website or from third parties. We also specifically coded the documents in the database and stamped paper documents as confidential when they were noted as Microsoft confidential within the document content. Further, as we coded data for origin and audience, the data coded as internally generated for internal audiences at MS was treated as confidential. In spite of this, as noted by Sandler and Blanck (2005), much information that would have been of use to the researchers was nevertheless not shared.

Besides procedures to safeguard confidentiality, we created security protocols and implementations within our technology to ensure security of the research data. If data were stored on computer hard drives, the computers were password protected. Copies of data on CD-ROMs were kept in locked, limited access offices. No other electronic copies of digital data were used. Printouts of files were limited in number with limited access. In short, because of the easy reproducibility of electronic information, we had to take extra, explicitly defined precautions to avoid inadvertent release of information.

Working with the electronic data in a secure environment was more difficult to set up. Any computer with access to the data required a password. Because of the magnitude of the data - 15,843 files total - a password-protected database was set up that kept track of individual file locations. A secure, web-based interface was designed to show the locations of the files and other metadata. Although the database and web pages used for this interface contained only metadata, not primary data files, they were housed on a computer (server) located in the researchers' office space to allow access via the Web. However, access to the database and web pages required passwords.

Other web-based tools required security. The FTP server to which some informants uploaded files was located in the researchers' office. Unique passwords were created for each informant's uploads to limit access to the server, and the accounts were disconnected shortly after documents were uploaded.

To foster trust in participants, as well as to ensure accuracy, all interviews were transcribed, reviewed by two other researchers for accuracy, and e-mailed to the participant using an e-mail address of the participant's choosing. Then, the 
interviewee reviewed the transcript, edited for accuracy, and marked sections that were either not to be disclosed publicly or not to be disclosed to MS. By request, one individual's interview and data provided were never put in digital form to avoid any possibility of inadvertent communication to individuals outside the research team.

\section{Managing Data}

This study collected 15,843 computer files from participants, which do not include data in other media (e.g. paper documents), interview transcripts, or web-based information and other information generated by the research team, such as notes. See Table 1 for a breakdown of files by data type. With this many files, one large task was to organize the files and provide access to them by type and other descriptive characteristics to facilitate a systematic approach to data analysis. Information retrieval must match researchers' needs with the documents in the database. Multimedia files are more difficult than text to store and retrieve and require new methods ( $\mathrm{Lu}, 1999)$. Creation of textual metadata is one method of storing and retrieving such data, and the one adopted in this project.

The organization of the data files as sent by the participants was maintained. For instance, some ways of transmitting files retain document characteristics, such as creation date, and these metadata were saved wherever possible. Each participant's files were kept in separate folders. A database set up in Microsoft SQL Server 2000 was created that contained the name and location of each data file. Fields were created to describe relevant file metadata. A web-based interface was developed to manage the database and to code the files. Figure 1 shows a sample of a web page displaying records of PowerPoint files in the database.

Initially, some file metadata could be culled from the file listing itself, especially for the files received via FTP and CD-ROM, where original file metadata tend to remain intact. These characteristics included the file name, file size, last modification date, and relative path to the file. In addition, the file format (e.g. Word document, PowerPoint slide, Excel spreadsheet) could usually be determined by the file extension (e.g., .doc, .ppt, or .xls, respectively). The main exception was e-mail, which usually was stored in plain text or Word files. Thus, a preliminary coding and generation of metadata including file characteristics file name, file size, last modification date, relative path, and file type was accomplished in the process of creating records for each file. Much of this could be performed automatically using database commands.

Once the database was created, a web page was created to allow coders to look at the contents of each file and add additional metadata about selected files. Figure 2 shows a sample of the coding page of a PowerPoint file record. Additional characteristics included the document title; document author; dates the document was saved, printed, and last edited; the author's organization; a brief description of the document; whether the document was generated by MS internally or by external individuals; and whether the audience was internal to MS.

Because this additional coding was performed by hand, it was done only for textbased information, including word processor documents (Word, WordPerfect, plain text), PowerPoint slides, publishing formats (Acrobat, Publisher), and e-mail. Many file characteristics, such as file printing date, file edit date, file author (as opposed to 
the person named in the document as the author), and author's organization, could be taken from the document Properties dialog box that is created in all Microsoft Office documents.

Once coded, these records could be sorted and searched by fields, and files could be accessed using this interface. However, to improve keyword search capabilities, because the internally developed search application was limited, the research team licensed a commercial search application, Enfish Find. Like many search engines (including Internet-based search engines) designed for large file sets, this search application "indexed" the information by key word, a time-consuming process that initially took several hours to complete. However, once indexed, the files could be searched by key word in one or two seconds. This permitted researchers to look easily for files - based on a keyword search — that related to research themes, such as incorporation of accessibility into software, the history of the accessible technologies group at MS, or the inclusion of individuals with disabilities into corporate culture.

Some documents in the dataset appeared more than once in different versions. Some of these showed edits by different people within and outside ATG. These edits might show up through the track changes option in Word, where different people's edits show in different colors and where the editor's name shows in a pop-up when the mouse cursor hovers over the change. Some editors changed the color of the text to show their input. Still others used the comment feature. For some documents, especially PowerPoint presentations, the different versions reflected the master document that had been modified for different audiences and speakers. Since many of these documents had been located in different folders and sometimes saved with different file names, using the database to locate the files saved time.

Problematic documents were e-mails, which often showed threads of communications that included several e-mail exchanges among several people saved in one document. Coding dates, the target audience, and even the authors was difficult and time consuming. On the other hand, contents of e-mails often could be taken directly from the subject lines, and sometimes a single file would document an extended discussion of a single issue. Examination of the document was necessary to determine whether the subject line reflected the content of the e-mail.

Notably, in this study of Microsoft many MS products were needed to view the data. Outside the IT industry, products of the company being studied would probably not be necessary to conduct the study. Inside the IT industry this phenomenon would likely be repeated, as many IT companies mandate the use of their products. In many others, the employees use what is readily available to them, which may be their own products. Companies may change the products they use as a result of mergers or acquisitions as well. Examples reported in the popular press include the following: AOL-Time Warner mandated the use of the AOL e-mail system for employees after their merger, supplanting the existing systems of communication within Time Warner. Units of IBM adopted Lotus Notes for internal employee communications after purchasing Lotus. Units of IBM adopted Linux for some internal corporate servers to lend credibility to its business services units, which sell Linux. Where proprietary or expensive internal systems are not available to researchers, access to data may be difficult or impossible, though access through corporate intermediaries might be available. As noted, in instances where software is used internally and not available to the public, and if data of interest to 
researchers are available only in those formats, the researchers will be dependent on the corporation for the ability to open the data files.

\section{IMPLICATIONS FOR RESEARCH}

\section{Dynamic Data}

Because digital files can be deleted, modified, moved, renamed, and the like, digital data are dynamic. As the MS researchers returned to data sources over time, they found that data had changed. In particular, Internet sources changed unpredictably, with pages moved or removed, portions of text subtly altered, and search engines returning differing results on subsequent days. Useful Internet documents had to be printed on paper or saved to disk to make them reliably available for future analysis, but even then, careful metadata (e.g. Web address, date printed) of the paper documents were needed. As a backup, the Web address (URL) was copied and pasted into a Word or HTML document, so that the Web page could be accessed again with a mouse click. A research database (Endnote Plus) was used to keep track of bibliographic information where Web addresses could be included. However, making the most current version of this database available to all researchers simultaneously was impractical since the version available at the time did not provide Internet or multiple-user features.

Another concern was the effect of study on the organization being researched. Frequently, researchers noticed changes in the Microsoft website that appeared to reflect discussions they had with contacts in the organization. Although no one on the research team was able to show a direct or indirect relationship between the researchers' ideas and the changes, the researchers became increasingly aware of possible interactions. As a result, less information was communicated by the researchers about their findings to participants during the course of the study.

\section{Emerging Technologies}

Electronic/digital research data have advantages over traditional types of data. Storage is relatively inexpensive and flexible, ranging from hard drives to writeable CD-ROMs and floppy disks. Multimedia, such as video, take significant storage space by current standards, but if sufficient digital storage is available, these types of information can be stored in one location, such as a single hard drive, where in the past multiple media sources required multiple storage devices, such as paper, disc, and audio- or videotape.

Ease of finding information, flexibility in storing and management, and ease with communications (e.g. file attachments) for digital information reduce the problems with data collection, decreasing data collection time and easing the burden on respondents. Some interviewees sent documents via e-mail attachments while the interview was in process, which was efficient for everyone. Also, direct quotations can be accurate where copy and paste operations extract the quotations directly from the data. 
New data types have disadvantages. Costs associated with applications and possible hardware needed for viewing and storage have been mentioned. Careful and flexible management of the data can be difficult, especially when the data need to be secure and data size requires storage on several media, as with huge video files. Further, the ease of accessing electronic data, especially Web-based information, can be seductive, especially when compared to difficult-to-access information from, say, the Library of Congress, which can take weeks to retrieve and must be dealt with immediately to avoid consequences for overdue materials. As a result, researchers must monitor their methodology to avoid a biasing preference for electronic information. Internet-based information in particular must be evaluated carefully for accuracy, reliability, and validity.

Researchers must take particular care with duplications. The same and similar file names can be used on widely different documents when large numbers of files make up a dataset. This can lead to difficulty distinguishing files in large searches. With another kind of duplication, different versions of the same document have different metadata (e.g. different file names, different modification dates) that do not necessarily provide clues to the similarity in content.

In this study, document organization and coding proved useful, though time intensive, allowing researchers to access files more easily and to know better what they were accessing. Documents could be searched and viewed by date ranges, which was helpful for getting a historical sense and the order that documents were created. They could be organized by author or target audience to give researchers a better idea about the people involved in the communications. Viewing different edited versions of the same document could inform researchers about the strategic thinking and corporate philosophy that generated the resulting documents, especially when documents included comments from several editors.

\section{The Corporate Culture}

The organizational chart provided by MS, however limited and out of date, was informative about the formal structure of the organization, showing in particular how individuals report to others in management. However, interviews indicated a less formal structure for the work process, where individuals were likely to choose a project to work on, or were assigned a project, and they were expected to do whatever was necessary to see that project to completion. Thus, going over a manager's head to accomplish a task could be supported, as long as the project was satisfactorily completed.

A review of e-mails and position papers supports this kind of organization. Recipients of e-mail, directly or through carbon copies, generally included names of peers within product groups, but often recipients included product managers and other employees outside the immediate product group. Similarly, documents intended for upper-level managers showed edits by peers as well as product managers and others.

This kind of collaboration and flexibility has advantages for people with disabilities because responding to an e-mail or marking up a digital document can allow extra time and care for those who have difficulty communicating orally, face to face. It also fosters a peer-level support system or mentoring system that could help 
people with certain types of disability to polish their communications before they are sent. This system allows greater use of assistive technology, and it may promote a greater level of parity with others in the organization.

On the other hand, researchers had to review thousands of documents to uncover some kinds of organizational information. It would have been hard to infer the organizational structure without the richer interview data. Further, since e-mail and collaborative works are essentially public documents (at least within the context of the organization), their content and tone may be different from private datacollection methods. Much that was discussed frankly in interviews would not have appeared in digital form because of the ease with which it could be disseminated to a wider audience.

Similar to collaborative works, other documents, especially PowerPoint presentations, were revised and recycled to different audiences. Subtle, or sometimes not so subtle, changes in approach, wording, and inclusion or exclusion of pages indicated interests and background of the audiences. When these audiences are comprised of individuals from product groups or levels of management, characteristics of the audiences can be inferred, such as their initial knowledge and level of interest in disability issues, information they wanted to obtain from the presentations, and what the presenter hoped they would gain from the presentation. It appeared that product groups had wide ranging backgrounds and levels of interest in developing accessible software, for example.

\section{Corporate Change}

Although the organization, mission, and personnel of the accessible technologies group at MS changed many times during the study, as it did many times during its decade or so of existence, current and former employees frequently expressed frustration at the difficulty of creating long term change in developing accessible software. On one hand, where they made great strides in helping Microsoft's major product lines become accessible by most standards, the system in which they work does not necessarily promote retention of changes from version to version. Many suggested that the most reliable way to ensure inclusion of accessibility would have to start from upper management, especially from the highest levels. This suggests the social nature of change in corporate culture, where at least the initial steps may need to be in understanding and influencing social forces within the organization. A study by the Society for Human Resource Management indicates that the best indicator of corporate culture change within an organization is involvement of the CEO with disability issues through personal experience (Bruyère, $1999^{5}$ ).

Because of the social nature of change in organizations, researchers should be careful about the myths and expectations of emerging technologies. For example, having more information does not necessarily mean that the research will be better or richer. In a cost-benefit sense, having better data management tools and skilled individuals to use them with large numbers of digital documents may not generate enough information to contribute meaningfully to the study. It is possible that a

\footnotetext{
${ }^{5}$ Results of this survey are currently available at http://www.worksupport.com/Archives/provisions.asp
} 
series of interviews will produce more informative and richer data than many more hours of reviewing e-mails. This is not to say that reading and coding e-mails is counterproductive, since it can provide primary data as well as valuable triangulation for interview and observational data. It can produce triangulation in the form of quantitative data, such as verifying the relative importance of a topic by the amount of information collected, or showing organizational structure by numbers of e-mails directed at individuals in an organization (Tyler et al., 2003).

Automated analysis of digital data might be beneficial. However, the computer science rule-garbage in, garbage out - is true. Automated methods of analyzing large amounts of data rely on an appropriate underlying methodology appropriately implemented. Otherwise, such methods can be misleading. For example, a keyword search for "Bill Gates" may produce hundreds of thousands of documents in a Web search engine, but even then the search is likely to miss "William Gates" or "Bill Gate". Even the careful researcher will be unable to ascertain the mistakes the original data sources might have that interfere with electronic searches. A human reading the words in context in those cases may be superior to the machine.

Even given limitations of electronic data and tools for examining such data sets, large, electronic data sets can be particularly valuable for research projects. Having the research readily available in an organized way to researchers at different locations through a secure, web-based interface can reduce time and costs associated with collection and analysis. A carefully designed interface can be extended over a wide area network or virtual network to enlarge the number of locations where the data are available. Once data are collected, they support and inform not only the particular research questions posed by the original researchers, but also, once the data are prepared for public viewing and given appropriate human subject protections, other researchers can mine the data to support other research questions.

\section{Future Technologies}

In a post-9/11, post-Enron era, where information security, corporate accountability, and corresponding government regulations affect corporate policies about information distribution and management, digital technologies will adapt accordingly, creating opportunities and challenges for researchers. Software requirements and features will restrict access to information by researchers unless they obtain permissions from corporate gatekeepers. Today, Microsoft Office, through its information rights management feature set, provides the capability to restrict documents from viewing or editing, which includes even portions of documents, unless access is granted. It has a feature that gives documents expiration dates, after which they are no longer viewable, except by the document creator (Microsoft, 2004c).

HIPAA, SEC, and NASD regulations will similarly affect information flow, storage, and management. Undoubtedly, at some point instant message client logs will be used in the study of corporate culture because they will be part of the "business records" of any corporation that uses the technology. However, like traditional business records, workers will maintain these technologies for formal records of business communications but gravitate toward other forms of communication for 
off-the-record transactions. Discovering such alternative forms of communication may continually be a moving target, as workers discover new ways transactions can be scrutinized publicly, possibly because of corporate security policies or legal proceedings. For example, the public nature of e-mail recently was highlighted by the brief publication on the Web of the entire Enron e-mail archive database, which included identifiable personal information, as part of a Federal Energy Regulatory Commission investigation (Berman, 2003).

On the other hand, technology can make information more accessible. The uses of mechanisms that allow easy distribution of information by individuals are continually developed and refined. The use of "blogs" (short for "Web logs"), a way for individuals easily to post information to a Web page similar to a diary, has been suggested as a way for real-time flow of information to corporate personnel, or even external audiences, without the overhead of e-mail (Farber, 2004). The increased use of centralized data storage may provide access to aggregate information but may also reduce individual user control over archived documents, which could affect retention of and access to ad hoc documents.

Technological changes affect how technology is used by people with disabilities, which opens up more and richer areas of exploration for researchers. IT is making inroads in fields requiring manual labor, reducing physical exertion in traditional manufacturing firms through the use of robotics to manipulate objects, for instance. Software automation increases opportunities for people with disabilities. Technologies such as calendars and scheduling software, or just-in-time training, could be useful to persons who need prompting to do particular tasks, or to do tasks in a certain order. Handheld devices, programmed accordingly, might replace job coaches in some instances.

Automation can eliminate or streamline repetitive tasks, as "macros" have done for traditional office work. This might reduce the need for interaction with input/ output systems, such as keyboards, for individuals with fine motor impairments. Other individuals may need assistance with directions to particular locations, a function with which mobile global positioning systems could assist. Systems that direct warehouse workers or stockers to locate items for storage or shipping could be implemented through IT solutions. Radio-frequency identification tags are used by some businesses to track and identify inventory and direct personnel to the right items.

Much needs to be learned about corporate culture-what it is, how it is manifested, how it changes, and how it affects the day-to-day operations of the organization. For those who want to learn more about corporate culture in large IT organizations and how to improve employment for people with disabilities, emerging technologies produce benefits and challenges for research. Potentially large amounts of information and innovative uses of technological solutions are two-sided coins that simultaneously offer the possibility of producing rich data that can be accessed and organized with great efficiency, as well as the likelihood of inefficiencies in discovering and viewing the best information in the data set. Researchers may find themselves dependent on the organizations they are researching for providing not only the data they need, but also mechanisms to access the data. Ultimately, however, for the social scientist, the objects under study are the social systems at work in the organizations. Adapting to emerging technologies will be an ongoing process to understand these underlying social systems. 


\section{REFERENCES}

Aldrich, H. (1999). Organizations evolving. London: Sage.

Atre, S. (1988). Data base: Structured techniques for design, performance, and management. New York: Wiley. Berman, D. K. (2003, Oct. 6). Online laundry: Government posts Enron's e-mail. Wall Street fournal, p. A1.

Blanck, P. D. (1996). Communicating the Americans with Disabilities Act. Transcending compliance: 1996 follow-up report on Sears, Roebuck and Company. Washington, DC: Annenberg Washington Program in Communications Policy Studies of Northwestern University.

Blanck, P., \& Marti, M. W. (1997). Attitudes, behavior, and the employment provisions of the Americans with Disabilities Act. Villanova Law Review, 42(2), 345-408.

Blanck, P., Ritchie, H., Schmeling, J. A., \& Klein, D. (2003a). Technology for independence: A community-based resource center. Behavioral Sciences and the Law, 21(1), 51-62.

Blanck, P. D., Schur, L., Kruse, D., Schwochau, S., \& Song, C. (2003b). Calibrating the impact of the ADA's employment provisions. Stanford Law and Policy Review, 14(2), 267-290.

Blanck, P. D., \& Turner, A. N. (1987). Gestalt research: Clinical field research approaches to studying organizations. In J. Lorsch (Ed.), The handbook of organizational behavior (pp. 109-125). New York: Prentice-Hall.

Boddy, D., \& Gunson, D. (1996). Organizations in the network age. London: Routledge.

Bogdan, R. C., \& Biklen, S. K. (1992). Qualitative research for education: An introduction to theory and methods (2nd ed.). Boston, MA: Allyn and Bacon.

Brem, S. K. (2002). Analyzing online discussions: Ethics, data, and interpretation. Practical Assessment, Research \& Evaluation, 8(3). Retrieved September 1, 2004, from http://pareonline.net/ getvn.asp?v $=8 \& \mathrm{n}=3$

Brown, J. S., \& Duguid, P. (2000). The social life of information. Boston: Harvard Business School Press.

Bruyère, S. M. (1999). ADA at work: Implementation of the employment provisions of the Americans with Disabilities Act (ADA): Survey of the Society for Human Resource Management executive summary. Alexandria, VA: SHRM.

Carr, N. G. (2003). IT doesn't matter. Harvard Business Review, 81(5), 41-49.

Carroll, G. R., \& Hannan, M. T. (2000). The demography of corporations and industries. Princeton, NJ: Princeton University Press.

Chin, A. G. (Ed.). (2001). Text databases and document management: Theory and practice. Hershey, PA: Idea Group.

Cross, E. Y., \& White, M. B. (1996). The diversity factor: Capturing the competitive advantage of a changing workforce. Chicago, IL: Irwin.

Czarniawska, B. (1997). Narrating the organization: Dramas of institutional identity. Chicago, IL: University of Chicago Press.

Edelman, L. B. (1990). Legal environments and organizational governance: The expansion of due process in the American workplace. American fournal of Sociology, 95(6), 1401-1440.

Edelman, L. B. (1992). Legal ambiguity and symbolic structures: Organizational mediation of civil rights law. American fournal of Sociology, 97(6), 1531-1576.

Edelman, L. B., Uggen, C., \& Erlanger, H. S. (1999). The endogeneity of legal regulation: Grievance procedures as rational myth. American fournal of Sociology, 105(2), 406-454.

Farber, D. (2004, February 22). What's up with blogging, and why should you care? ZDNet Tech Update Today. Retrieved February 25, 2004, from http://techupdate.zdnet.com/techupdate/stories/main/ What_is_up_with_blogging.html

Fisher, I., \& Gangolly, J. (2001). Markup languages and electronic commerce. In A. G. Chin (Ed.), Text databases and document management: Theory and practice (pp. 1-21). Hershey, PA: Idea Group.

Fortune. (2002a). The 2002 Fortune 500: America's largest corporations. (on file with author).

Fortune. (2002b). The 2002 Fortune 500 industry rankings: Computer software. (on file with author).

Fuller, S. R., Edelman, L. B., \& Matusik, S. (2000). Legal readings: Employee interpretation and enactment of civil rights law. Academy of Management Review, 25(1), 200-216.

Gilbert, J., \& Ivancevich, J. (2000). Valuing diversity: A tale of two organizations. Academy of Management Executive, 14(1), 93-105.

Hayles, V. R., \& Russell, A. M. (1997). The diversity directive: Why some initiatives fail and what to do about it. Chicago, IL: ASTD, Irwin.

Headd, B. (2000). The characteristics of small-business employees. Monthly Labor Review, 123(4), $13-18$.

Hofstede, G. (1991). Cultures and organizations: Software of the mind. Maidenhead: McGraw-Hill.

Information Technology Association of America. (2003). Report of the ITAA Blue Ribbon Panel on IT diversity. Retrieved on September 1, 2004, from http://www.itaa.org/workforce/docs/03divreport.pdf

Knowling, R. (2003). Keynote speech. 2003 National IT Workforce Convocation. Arlington, VA. 
Kochan, T., Bezrukova, K., Ely, R., Jackson, S., Joshi, A., Jehn, K., Leonard, J., Levine, D., Thomas, D. (2003). The effects of diversity on business performance: Report of the diversity research network. Human Resource Management, 42, 3-21.

Kruse, D. (2001). Commentary. In S. T. Doherty et al. (Eds.), Telework: The new workplace of the 21st century (pp. 98-102). Washington, DC: U.S. Department of Labor.

Lazear, E. P. (1995). Corporate culture and the diffusion of values. In Horst Siebert (Ed.), Trends in business organization: Do participation and cooperation increase competitiveness? (pp. 89-133). Tübingen: Mohr.

Lu, G. (1999). Multimedia database management systems. Norwood, MA: Artech.

Mazrui, J. (1995). Some history of the GUI struggle. Retrieved August 31, 2004, from http:/groups.google. com/groups?selm = 51D59D01132\%40ksgdfs.harvard.edu\&oe $=\mathrm{UTF}-8 \&$ output $=$ gplain

Mazrui, J. (1996). Windows 95 accessibility. Retrieved August 31, 2004, from ftp://ftp.icdi.wvu.edu/MISC/ WIN95ACC.TXT

Meyerson, D. E. (2001). Tempered radicals: How people use difference to inspire change at work. Boston: Harvard Business School Press.

Microsoft. (2004a). Fast facts about Microsoft. Retrieved September 1, 2004, from http://www. microsoft.com/presspass/inside_ms.asp

Microsoft. (2004b). Diversity at Microsoft. Retrieved September 1, 2004, from http://www.microsoft.com/ mscorp/citizenship/diversity/

Microsoft. (2004c). Office 2003 editions: Compare them to previous versions. Retrieved September 1, 2004, from http://www.microsoft.com/office/editions/prodinfo/compare.mspx

Microsoft. (2004d). Employee resource groups. Retrieved September 2, 2004, from http://www. microsoft.com/mscorp/citizenship/diversity/inside/dac.asp

Murphy, L. D. (2001). Addressing the metadata gap: Ad hoc digital documents in organizations. In A. G. Chin (Ed.), Text databases and document management: Theory and practice (pp. 52-77). Hershey, PA: Idea Group.

National Organization on Disability. (2000). The 2000 N.O.D./Harris survey of Americans with disabilities. Washington, DC.

Prasad, P., Mills, A. J., Elmes, M., \& Prasad, A. (1997). Managing the organizational melting pot: Dilemmas of workplace diversity. Thousand Oaks, CA: Sage.

Sandler, L., \& Blanck, P. (2005). Accessibility as a corporate article of faith at Microsoft: Case study of corporate culture and human resource dimensions. Behavioral Sciences and the Law (this issue).

Sarbanes-Oxley Act of 2002 (Public Company Accounting Reform and Investor Protection Act) (codified in scattered sections of Titles $15 \& 18)$ (2002).

Schartz, K., Schartz, H., \& Blanck, P. (2002). Employment of persons with disabilities in information technology jobs: A literature review for 'IT Works.' Behavioral Sciences and the Law, 20, $637-657$.

Schein, E. H. (1985). Organizational culture and leadership: A dynamic view. San Francisco: Jossey-Bass.

Schein, E. H. (1986). What you need to know about organizational culture. Training and Development fournal, 2(3), 30-33.

Schein, E. H. (1999). The corporate culture survival guide: Sense and nonsense about culture change. San Francisco: Jossey-Bass.

Schein, E. H. (2000). Sense and nonsense about culture and climate. In N. M. Ashkanasy, C. P. M. Wilderom, \& M. F. Peterson (Eds.), Handbook of organization culture and climate (pp. xxiii-xxx). Thousand Oaks, CA: Sage.

Schur, L. A. (2002). Dead-end jobs or a path to economic well-being? The consequences of non-stand ard work among people with disabilities. Behavioral Sciences and the Law, 20(6), 601-620.

Schur, L. (2003). Barriers or opportunities? The causes of contingent and part-time work among people with disabilities. Industrial Relations, 42(1), 31-66.

Schur, L., Kruse, D., \& Blanck, P. (2005). Corporate culture and the employment of persons with disabilities. Behavioral Sciences and the Law (this issue).

Silverstein, R., Julnes, G., \& Nolan, R. (2005). What policymakers need and must demand from research regarding the employment rate of persons with disabilities. Behavioral Sciences and the Law (this issue).

Tyler, J. R., Wilkinson, D. M., \& Huberman, B. A. (2003). Email as spectroscopy: Automated discovery of community structure within organizations. Retrieved September 1, 2004, from http://www.hpl.hp.com/ research/idl/papers/email/email.pdf

U.S. Department of Education. (n.d.). NIDRR's research program. Retrieved August 31, 2004, from http://www.ed.gov/rschstat/research/pubs/res-program.html

U.S. General Accounting Office. (1996). SSA disability: Program redesign necessary to encourage return to work (GAO/HEHS-96-62). Washington, DC.

U.S. General Accounting Office. (1997). Social security: Disability programs lag in promoting return to work (GAO/HEHS-97-46). Washington, DC. 
U.S. General Accounting Office. (1998a). Social security disability insurance: Factors affecting beneficiaries' return to work (GAO/T-HEHS-98-230). Washington, DC.

U.S. General Accounting Office. (1998b). Social security disability insurance: Multiple factors affect beneficiaries' ability to return to work (GAO/HEHS-98-39). Washington, DC.

U.S. General Accounting Office. (2001). SSA disability: Other programs may provide lessons for improving return-to-work efforts (GAO-01-153). Washington, DC.

U.S. General Accounting Office. (2002a). Business tax incentives: Incentives to employ workers with disabilities receive limited use and have an uncertain impact (GAO-03-39). Washington, DC.

U.S. General Accounting Office. (2002b). SSA disability: SGA levels appear to affect the work behavior of relatively few beneficiaries, but more data needed (GAO-02-224). Washington, DC. 